\title{
Effects of lung resection on pulmonary function and exercise capacity
}

\author{
Clarence Pelletier, Linda Lapointe, Pierre LeBlanc
}

\begin{abstract}
The effects of lung resection on exercise capacity and perception of symptoms were studied in 47 patients aged 39-73 (mean 58.3) years. Twenty had a pneumonectomy and 27 a lobectomy, all for lung cancer. Forced expiratory volume, maximal inspiratory and expiratory pressures, and progressive maximal one minute incremental cycle ergometer exercise performance were measured before and after surgery. Breathlessness and leg discomfort were assessed with a modified Borg scale (0-10). Mean FEV decreased from $79 \%$ (SD $22 \%$ ) to $53 \%$ $(11 \%)$ of the predicted value after pneumonectomy and from $89 \%(22 \%)$ to $74 \%(18 \%)$ after lobectomy. Exercise capacity, measured as the highest work load completed, $\dot{W} \max$, decreased from $78 \%(25 \%)$ to $58 \%(28 \%)$ predicted in the pneumonectomy group and from $\mathbf{7 7 \%}$ $(21 \%)$ to $67 \%(20 \%)$ in the lobectomy group. There was only a weak relation between changes in $F E V_{1}$ and changes in $\dot{W} \max \left(r=0.54, r^{2}=0.30\right)$. The slope of the relation between the intensity of dyspnoea and work load or the intensity of dyspnoea and ventilation increased significantly after pneumonectomy, but not after lobectomy. Leg discomfort increased more rapidly when related to work load after both pneumonectomy and lobectomy. After resection dyspnoea was rarely the only limiting factor at maximal exercise. It is concluded that (1) change in $F E V_{1}$ is a poor predictor of change in exercise capacity after lung resection; (2) pneumonectomy results in a $25 \%$ decrease in $\dot{W} \max$ and in an appreciable increase in dyspnoea during exercise; (3) lobectomy has little or no effect on $\dot{W} \max$ or the intensity of postoperative dyspnoea; (4) after both pneumonectomy and lobectomy leg discomfort makes an important contribution to exercise limitation.
\end{abstract}

Centre de

Pneumologie, Hôpital

Laval, Ste-Foy,

Québec, Canada

C Pelletier

L Lapointe

$P$ LeBlanc

Address for reprint requests: Dr Pierre LeBlanc, Centre de Pneumologie, 2725 Chemin Ste-Foy, SainteFoy, Quebec, Canada.

Accepted 22 February 1990 to tolerate exercise and thus affect his quality of life. Previous studies have evaluated the changes in exercise capacity after lung resection; but these studies did not always include
Surgery is the recommended treatment for lung cancer whenever possible. Resection of lung parenchyma decreases ventilatory preoperative assessments, ${ }^{1-3}$ and many included patients with tuberculosis, some of whom had had a previous thoracoplasty. ${ }^{4-6}$ Only one study has examined the changes in maximum ventilation after pneumonectomy, using a similar assessment before and after surgery, ${ }^{7}$ and only one study has examined the effects of lung resection on the perception of symptoms during exercise and its relation to exercise limitation and the assessment was qualitative. ${ }^{8}$ Quantification of these symptoms and an understanding of their aetiology are necessary for determining which treatment produces optimal functional capacity after lung resection.

In the present study we evaluated the effects of lung resection on (1) ventilatory and exercise capacity and (2) the intensity of symptoms (dyspnoea and leg discomfort) during exercise.

\section{Methods}

SUBJECTS

We studied prospectively 56 patients undergoing surgery for lung cancer. There were 49 men and seven women, aged 39-75 (mean $59.0)$ years. All were considered to have technically resectable tumours according to clinical, radiographic, and bronchoscopic criteria. Twenty four patients had a pneumonectomy and 32 a lobectomy. Nine patients were dropped from the study after the postoperative evaluation because of claudication (five patients), submaximal effort (1), thoracic pain (1), depression (1), and upper airway infection (1). Four of the nine patients had had a pneumonectomy and five a lobectomy. They did not differ in age or initial $\mathrm{FEV}_{1}$ from the 47 patients who completed the study. Informed consent was obtained from all patients.

\section{APPARATUS}

Spirometry (FVC, $\mathrm{FEV}_{1}, \mathrm{FEV}_{1} / \mathrm{FVC}$ ratio) was performed with a rolling seal spirometer (PK Morgan). Maximal inspiratory pressure (MIP) and maximal expiratory pressure (MEP) were measured according to the technique described by Black and Hyatt, ${ }^{9}$ an anaeroid manometer (Boehringer, No 7273) being used. Subjects exercised on an electrically stabilised cycle ergometer (Quinton Instruments, No 845). Minute ventilation ( $\dot{V} E)$ was measured with a low resistance turbine (volume cartridge, Sensor Medics, No 
764040), and heart rate was monitored throughout exercise with a modified V5 ECG lead. The equipment was calibrated before each test.

PROCEDURE

Each subject was evaluated twice, before and after operation. Spirometric indices and maximal inspiratory and expiratory pressures were measured before each exercise test. After resting for two minutes sitting on the cycle the subjects performed a symptom limited exercise test under medical supervision, the load being increased by $100 \mathrm{kpm} / \mathrm{min}$ each minute to maximal capacity. ${ }^{10}$ Subjects were asked to maintain a constant speed at $60 \mathrm{revs} / \mathrm{min}$. They were asked to evaluate the magnitude of their breathlessness and leg discomfort separately on a modified Borg scale at the end of each minute of exercise. They selected a number from 0 to 10 for each symptom, 0 being the absence of symptoms and 10 the maximum bearable. ${ }^{11}$ Ventilation and heart rate were recorded during rest and throughout exercise. Measurements obtained during the second half minute at each work load were used for analysis.

\section{ANALYSIS OF DATA}

$\mathrm{FEV}_{1}$ and maximal exercise capacity-that is, the last work load completed (W $\max$ )-are expressed as percentages of the predicted values of Berglund ${ }^{12}(\mathrm{FEV} \%)$ and Jones et $^{\mathrm{al}} \mathrm{l}^{13}$ $\left(\dot{W} \max ^{\circ}{ }_{0}\right)$ respectively. Maximal ventilation ( $\dot{V} \max )$ is the ventilation measured at $\dot{W} \max$. The maximal indirect voluntary ventilation

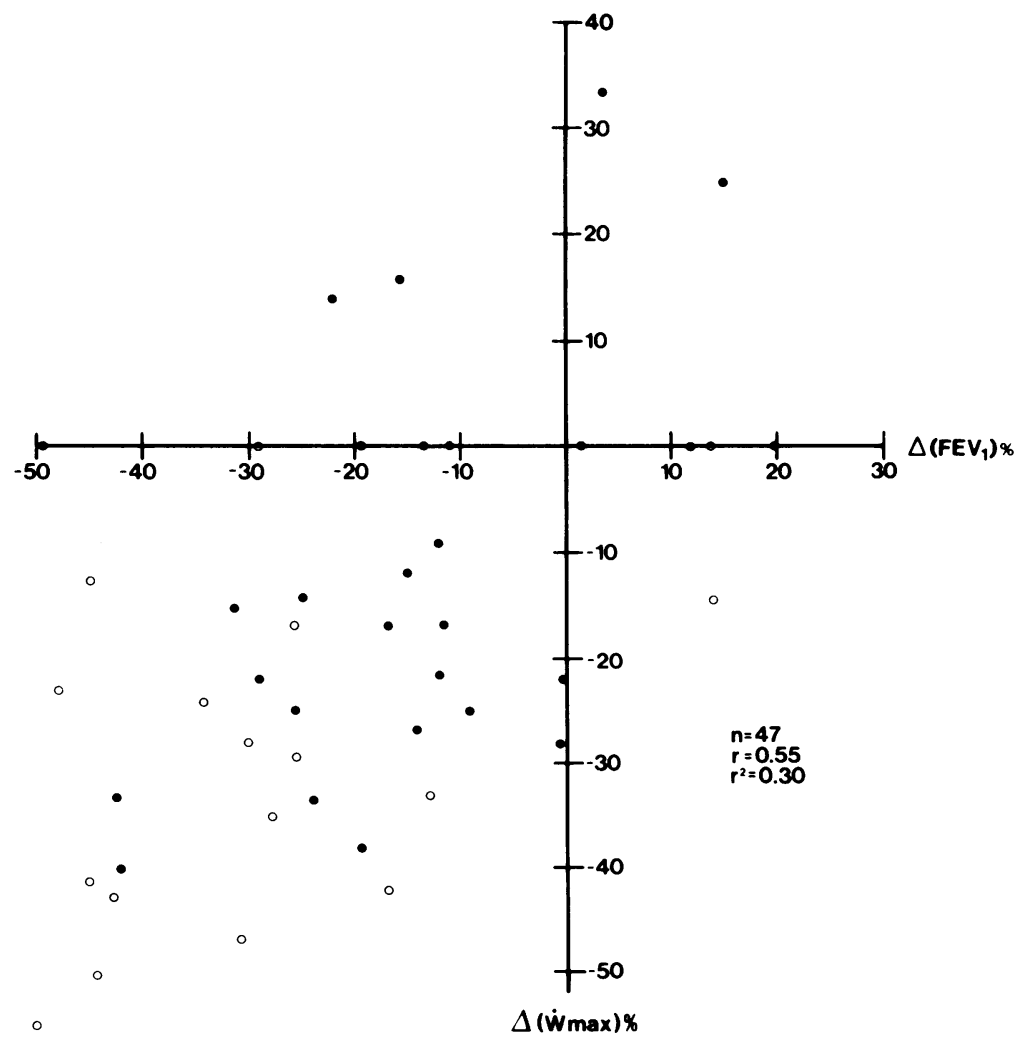

Figure 1 Relation between change in exercise capacity and change in $F E V_{1}$, both expressed as percentages of initial values. Wmax-maximal exercise intensity. The black dots indicate lobectomy and the white dots pneumonectomy.
(MVV) was calculated from the formula $\mathrm{FEV}_{1}$ $\times 35 .{ }^{14}$ The heart rate response was analysed by a least square linear regression with the work load, expressed as \% predicted, as the independent variable. We used this method because heart rate increases linearly with work load from rest to maximal exercise. ${ }^{15} \mathrm{We}$ calculated heart rate at $50 \%$ of the predicted maximal work load $\left(\mathrm{HR}_{50}\right)$ from the regression equation.

The relation between (1) intensity of dyspnoea versus work load; (2) leg discomfort versus work load; (3) ventilation versus work load, and (4) the dyspnoea score and ventilation were analysed by the least square linear regression method with the second measure as the independent variable. To increase the linearity of the relation, only the points where the Borg score was above 0 were included. To take into account the interrelation between symptoms (breathlessness or leg discomfort) and work load, work load was normalised to calculate the intercept. For each relationship we then calculated the slope and the intercept for each subject and the mean and standard deviation was calculated for the pneumonectomy and the lobectomy group before and after operation. The groups were compared in terms of the slope and the intercept by means of a Wilcoxon signed rank $t$ test. Two patients in the pneumonectomy group and six in the lobectomy group were excluded from this part of the analysis because they could not understand or read the modified Borg scale.

\section{Results}

EFFECTS OF LUNG RESECTION ON FEV

Preoperative $\mathrm{FEV}_{1}$ varied from $42 \%$ to $127 \%$ predicted in the lobectomy group and from $41^{\circ}$ o to $121 \%$ in the pneumonectomy group. Sixteen patients had an initial $\mathrm{FEV}_{1}$ lower than $70 \%$ predicted. The postoperative evaluation was done 29-200 (mean 73.2) days after resection in the lobectomy group and 26141 (mean 62.2) days in the pneumonectomy group. The mean $\mathrm{FEV}_{1}$ ( $\%$ predicted) decreased from 89 (SD (22) to 74 (10) after lobectomy and from $79(22)$ to 53 (11) after pneumonectomy. This represents a mean decrease of $17 \%$ in the lobectomy group and $31^{\circ}$ in the pneumonectomy group. The fall in $\mathrm{FEV}_{1} \%$ predicted was significant for both groups $(\mathrm{p}<0.001)$.

There was no significant difference between MIP before and after operation ( 77.7 (SD $30 \cdot 2)$ to $\left.73 \cdot 1(32 \cdot 0) \mathrm{cm} \mathrm{H}_{2} \mathrm{O}\right)$ or MEP $(100 \cdot 4$ $(32 \cdot 3)$ to $91 \cdot 6(31 \cdot 2) \mathrm{cm} \mathrm{H}_{2} \mathrm{O}$ ).

\section{EFFECTS OF LUNG RESECTION ON RESPONSE TO EXERCISE}

Preoperative $\dot{W} \max (\%$ predicted) varied from 47 to 123 in the lobectomy group and from 41 to 163 predicted in the pneumonectomy group. Mean W $\max$ decreased from $77(21)$ to $67(20)$ after lobectomy, and from 78 (25) to 58 (28) predicted after pneumonectomy. This represents a mean decrease of $12 \%$ from the preoperative value in the lobectomy group and of $26 \%$ in the pneumonec- 


\section{Pneumonectomy}

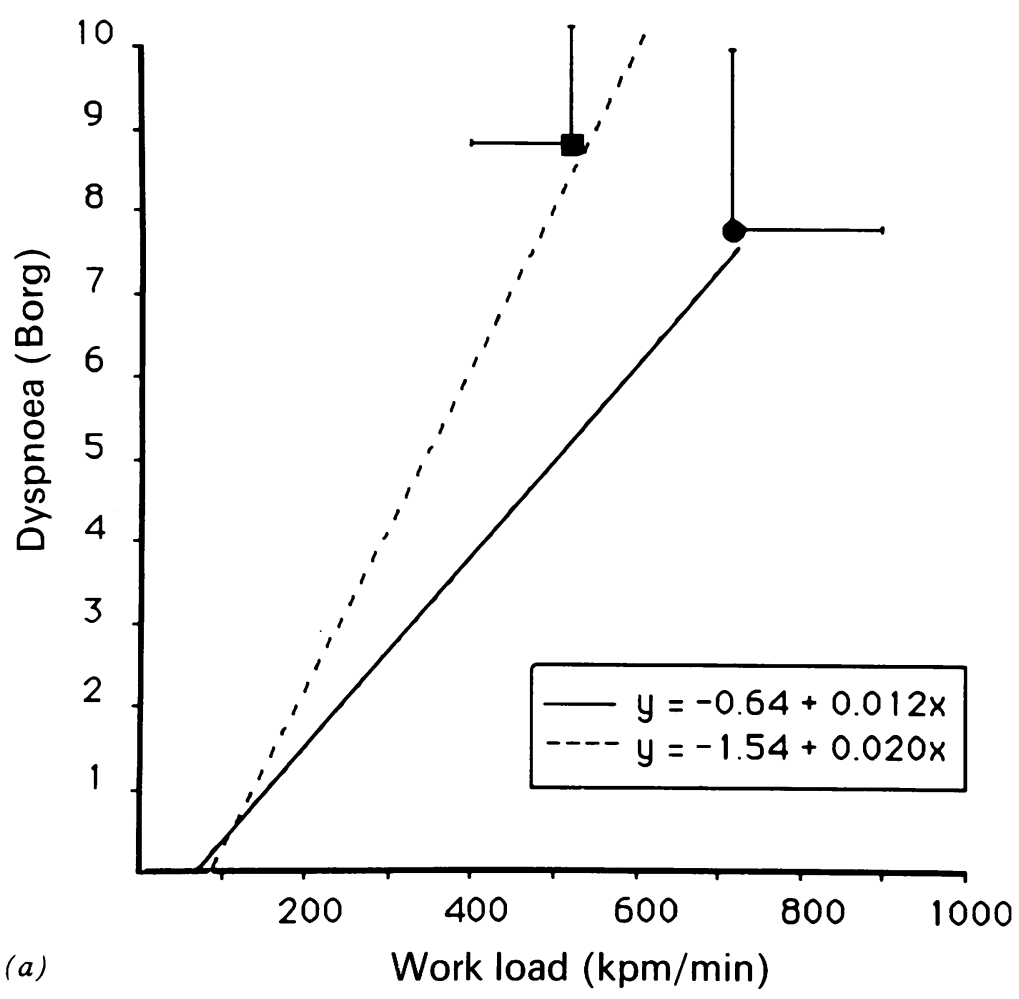

(a)

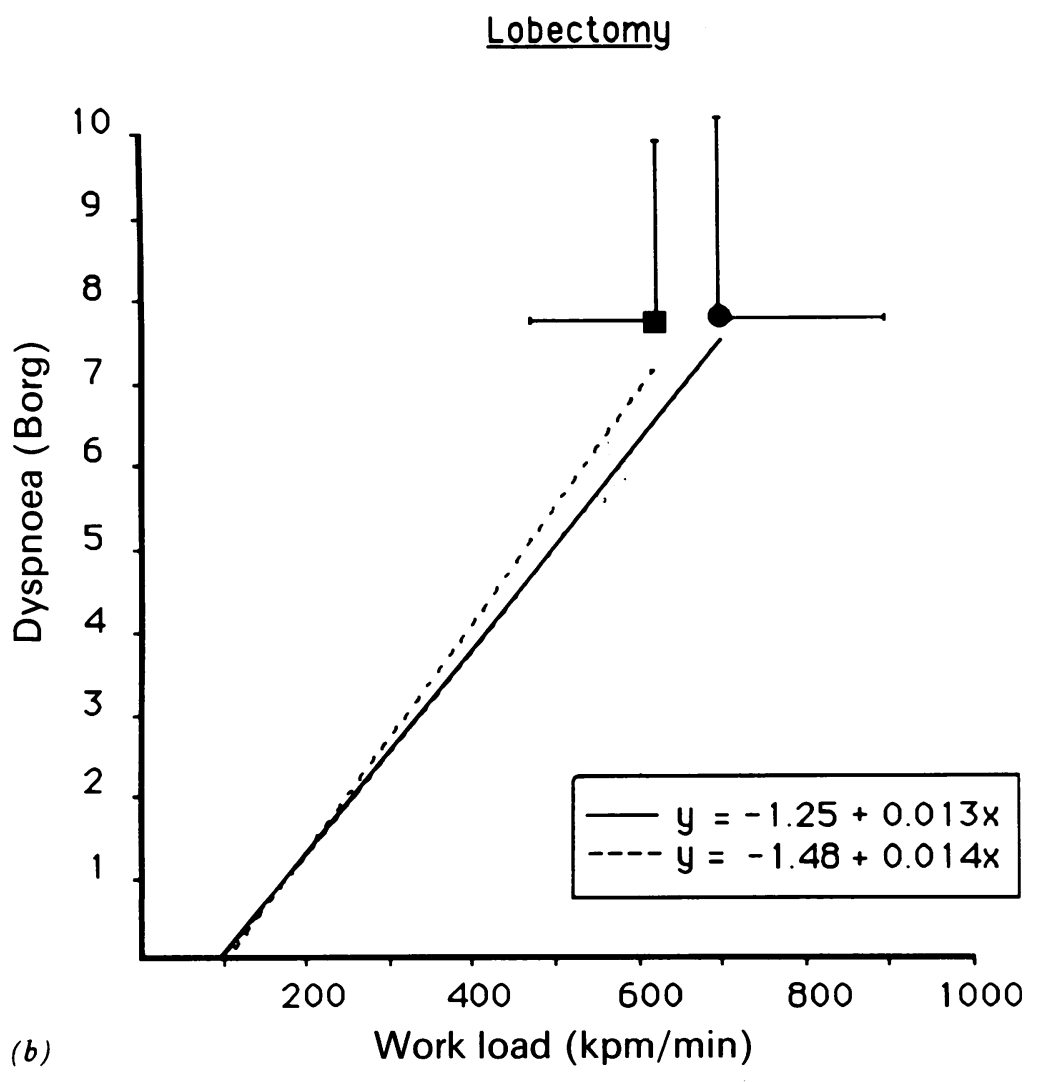

Figure 2 Relation between the intensity of dyspnoea (Borg scale) and work load ( $\mathrm{kpm} / \mathrm{min}$ ) before (continuous line) and after (dotted line) resection. The slope increased significantly $(p<0.01)$ after pneumonectomy (a) but not after lobectomy (b). The mean and SD maximal work loads (Wmax) and the dyspnoea score at maximal exercise intensity are also shown. Before resection; 1 after resection. tomy group. The fall in $\dot{W} \max \%$ predicted was significant for both groups $(\mathrm{p}<0.001$ ). There was no correlation between the fall in $\dot{W} \max { }^{o}$ o predicted and the period that had elapsed since resection $(r=0 \cdot 22)$.

There was a significant correlation between change in $\mathrm{FEV}_{1}$ and change in $\dot{\mathrm{W}} \max$, both expressed as a percentage of the preoperative value $(\mathrm{r}=0.55, \mathrm{p}<0.001$, fig 1$)$. The $\triangle \mathrm{FEV}_{1} \%$ predicted accounted for only $30 \%$ of the variance in $\triangle \dot{W} \max \%$ predicted. The correlation was better in the 16 patients with a preoperative $\mathrm{FEV}_{1}$ below $70 \%$ predicted $(r=0.82)$ than in the 31 patients with an initial $\mathrm{FEV}_{1}$ above $70 \%(\mathrm{r}=0.46)$.

The preoperative $\mathrm{HR}_{50}$ increased from 118.9 (SD 15.3) to $121.3(13.0)$ beats/min after lobectomy (NS) and from $123.9(13.9)$ to $128.5(12.0)$ beats/min after pneumonectomy (NS). $\dot{\mathrm{V} m a x} /$ $\mathrm{MVV}^{\circ}{ }_{0}$ increased from $66.4(13.2)$ to 71.0 $(11 \cdot 2)$ (NS) after lobectomy and from 72.5 (18.6) to $82.6(16.5)(\mathrm{p}=0.02)$ after pneumonectomy.

\section{EFFECTS OF LUNG RESECTION ON SYMPTOMS}

The mean relation between the intensity of dyspnoea and the work load for all subjects before and after pneumonectomy and lobectomy is shown in figure 2 . The slope increased after pneumonectomy $(0.012$ (SD 0.004) to $0.020(0.007), p<0.01)$ but not after lobectomy $(0.013(0.005)$ to $0.014(0.007), p=N S)$. The mean relation between the intensity of leg discomfort and the work load for each group is shown in figure 3. There was an increase in slope after pneumonectomy $(0.0115(0.005)$ to $0.0180(0.008), \mathrm{p}<0.01)$ and after lobectomy $(0.014(0.004)$ to $0.017(0.008), \mathrm{p}<0.01)$.

There was no change in the relation between ventilation and the work load, before and after operation, in either group. The slope of the relation between dyspnoea and ventilation was greater after pneumonectomy $(0.175(0.090) v$ $0 \cdot 298$ (0.140): fig 4); there were no significant changes after lobectomy.

After lung resection one of the 21 patients evaluable in the lobectomy group and four of 18 patients evaluable in the pneumonectomy group stopped exercise because of dyspnoea only; a combination of the two symptoms (dyspnoea and leg discomfort) was the most frequent factor limiting exercise in both groups (fig 5).

\section{Discussion}

In this study $\mathrm{FEV}_{1}$ and exercise capacity decreased significantly after lung resection. The decrease in $F E_{1}$ is in agreement with previous studies. ${ }^{16}$ as expected, we observed a correlation between the changes in the two measurements, ${ }^{1617}$ although the change in FEV $_{1}$ could explain only $30 \%$ of the change in exercise capacity after lung resection. This figure was higher in patients with a lower preoperative $\mathrm{FEV}_{1}$. In a few patients exercise capacity barely changed after surgery even though they had lost $30-50 \%$ of their ventilatory capacity. 


\section{Pneumonectomy}

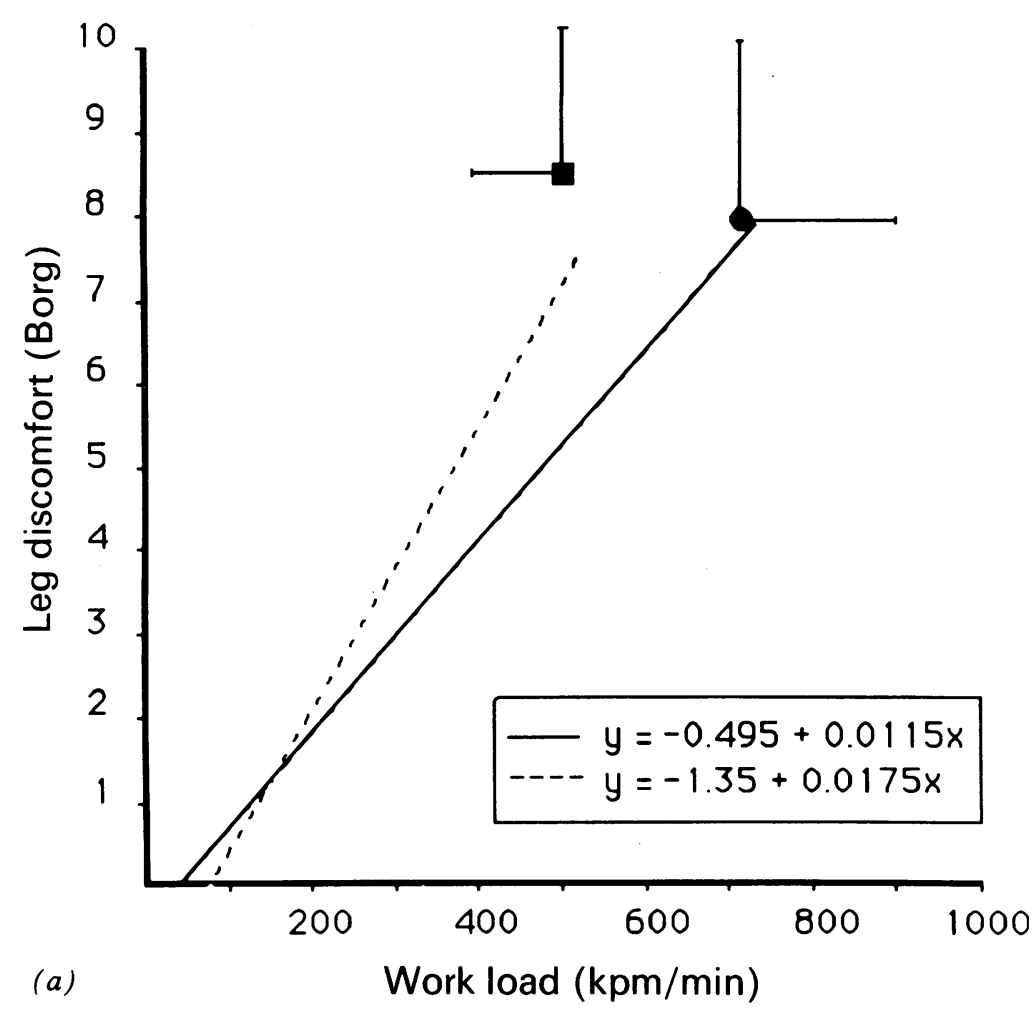

\section{Lobectomy}

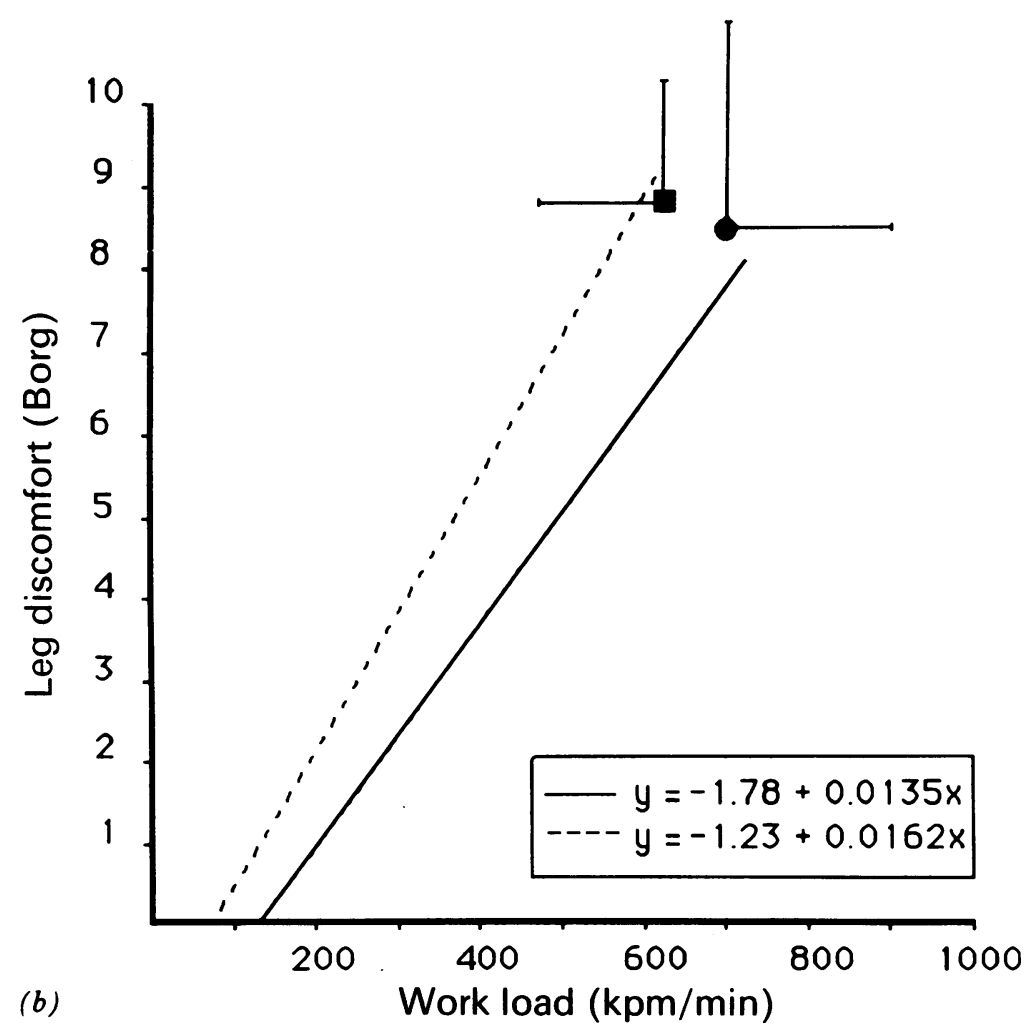

Figure 3 Relation between leg discomfort (Borg scale) and work load ( $\mathrm{kpm} / \mathrm{min}$ ) before and after resection. The slope increased significantly after pneumonectomy (a) and lobectomy (b). The mean (and SD) work loads and dyspnoea scores at maximal exercise intensity are also shown.
A few points are open to criticism. The postoperative assessment was performed early after surgery. The fall in exercise capacity in our group is similar to that of a previous study, however, which indicated that a major underestimation in measurement is unlikely. ${ }^{16} \mathrm{~A}$ previous study has shown that changes in pulmonary function (no exercise test was performed) were greatest in the first and second postoperative weeks and had returned to predicted normal values between the fourth and the sixth week after thoracotomy in patients undergoing segmental resection, though some patients had not yet completely returned to their preoperative value 10 weeks after operation. ${ }^{18}$ None of our 47 patients was limited by thoracic pain during the postoperative evaluation.

The reproducibility of the cycle ergometer exercise test is not precisely known. One report showed $8^{\circ}$, variability in two consecutive tests, ${ }^{19}$ and more recently Kyle et al showed an $11^{\circ}{ }_{0}$, within subject variability in three consecutive exercise tests on a treadmill. The variability was not influenced by the level of training. ${ }^{20}$ The reproducibility of the results obtained from the modified Borg scale in the evaluation of dyspnoea during exercise has been reported once. ${ }^{21}$ The authors showed that results based on this scale were as reproducible as any of the other physiological measurements carried out during exercise $(6-10 \%)$. We cannot eliminate a learning effect, but the agreement between the fall in exercise capacity observed in our subjects and those reported previously suggests that a learning effect was not important.

The least squares linear regression method was used to analyse the effects of lung resection on symptoms. Previous studies have shown that the relation between symptoms and work load and between dyspnoea and ventilation are approximately linear. ${ }^{22}$

Dyspnoea increased significantly for a given work load after pneumonectomy whereas there was no significant change after lobectomy. Boushy et al reported that the number of patients who developed worsening dyspnoea after lobectomy and pneumonectomy was similar. ${ }^{8}$ They used only a semiquantitative evaluation of dyspnoea, however (a questionnaire on daily activities). Our study evaluated dyspnoea with the same scale throughout exercise.

The observation that patients undergoing pneumonectomy had an appreciable fall in respiratory reserve, as shown by the fall in the ratio Vmax:MVV, is probably not the only factor contributing to the increase in the slope of the relation between breathlessness and ventilation. Several mechanisms other than mechanical factors contribute to respiratory effort, each varying in extent between individuals. These include the strength and operating characteristics of the respiratory muscles (length-tension and force-velocity characteristics), the mechanical impedance opposing their action, cooperation between muscle groups, complex geometric factors, and the presence or absence of fatigue..$^{22}$ All these 
components need to be considered to predict the effect of lung resection on perception of symptoms after surgery.

The intensity of leg fatigue increased in both groups and after lung resection it frequently limited exercise capacity. Leg fatigue increased as much as breathlessness after lung resection, especially after lobectomy. Leg fatigue has been shown to contribute significantly to the

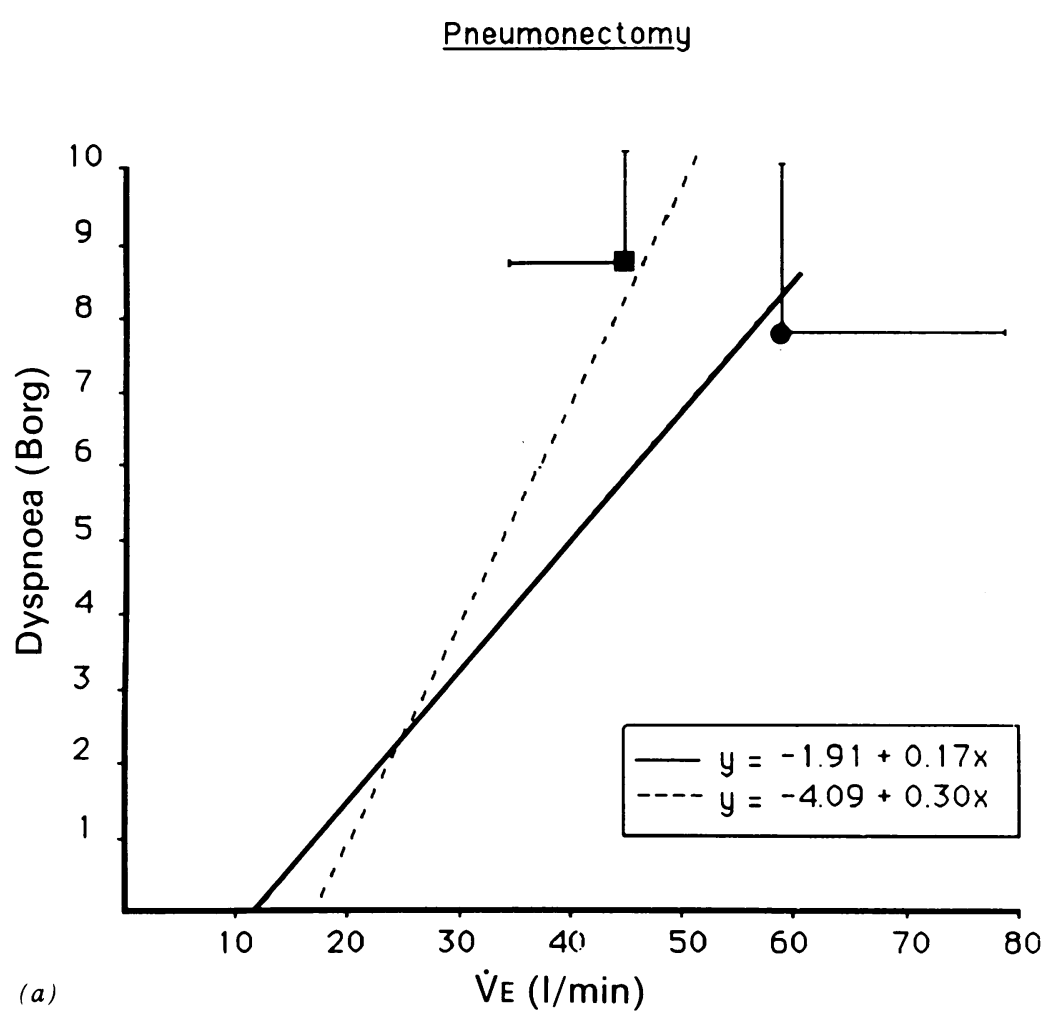

Lobectomy

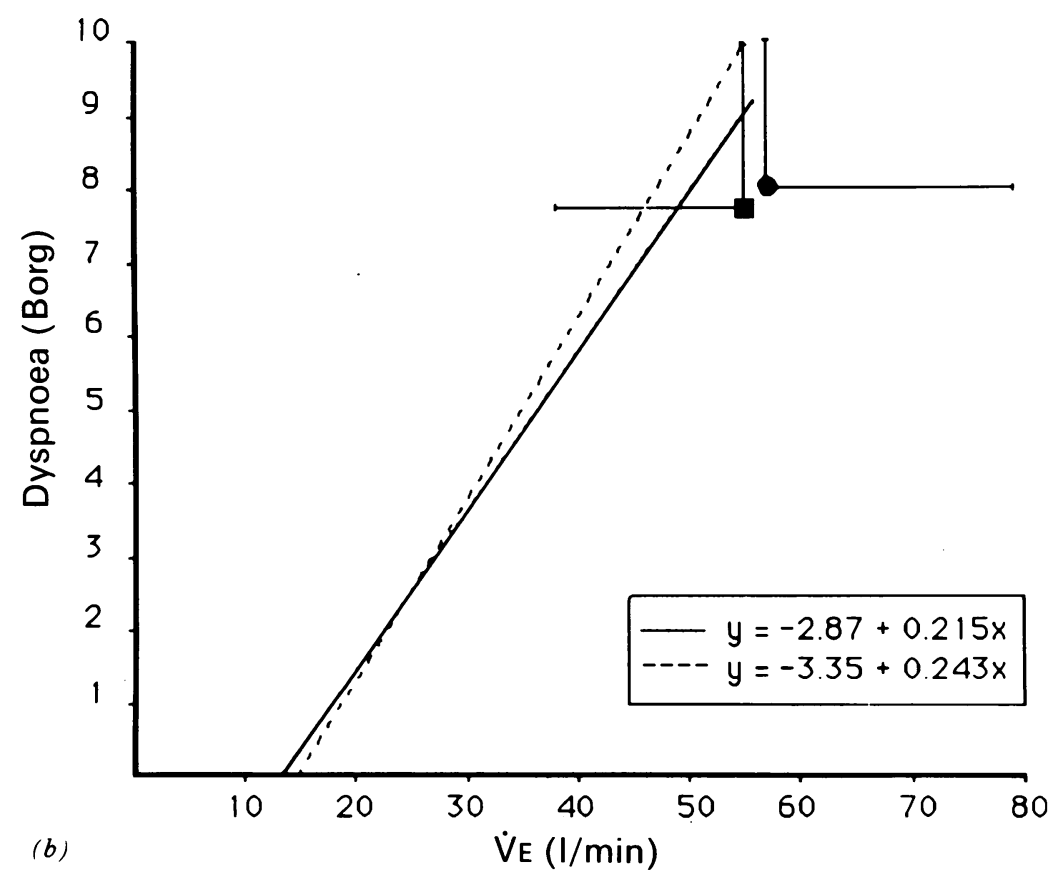

Figure 4 Relation between the intensity of dyspnoea (Borg scale) and ventilation ( $\dot{V}_{E}$ ) during exercise before and after resection. There was a significant increase in the slope after pneumonectomy (a) but not after lobectomy (b). The mean (and SD) ventilation and the dyspnoea scores at maximal exercise intensity are also shown.
No of

subjects
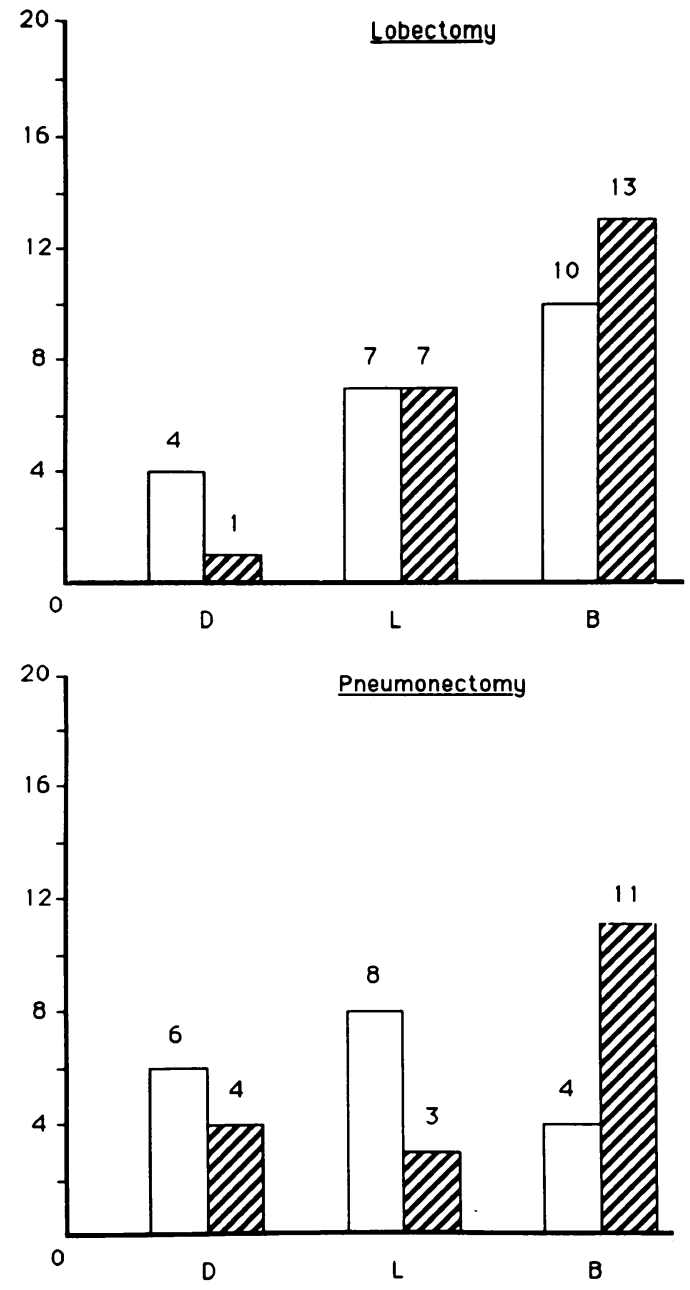

Figure 5 Number of patients having the highest symptom score for dyspnoea $(D)$, leg discomfort $(L)$, or both symptoms $(B)$ at maximal exercise intensity before (clear bars) and after (dashed bars) lung resection.

limitation of exercise capacity in patients with severe airflow limitation. ${ }^{23}$ In the present study leg discomfort may be secondary to the muscle deconditioning following major surgery. There were no significant changes in MIP and MEP after operation, suggesting that the respiratory muscles were not weakened. Respiratory muscles, however, are more resistant to fatigue than are peripheral muscles. ${ }^{25}$

The fact that we evaluated our patients so soon after surgery may have contributed to increased leg discomfort during exercise. Most of them were sedentary, however, before surgery and inactivity after surgery was not prolonged. They were mobilised within 24 hours of surgery and were discharged rapidly (mean 12 (SD 4) days). The absence of any relation between the time that had elapsed since surgery and the fall in exercise capacity suggests that early postoperative evaluation was not the major cause of exercise limitation. The increased intensity of leg discomfort also suggests that postoperative rehabilitation should begin soon after surgery to increase exercise tolerance.

A decrease in cardiac output and poor peripheral perfusion could have contributed to the 
exercise limitation, though the absence of significant changes in $\mathrm{HR}_{50}$ after pneumonectomy suggests that this was unlikely. One previous study showed indirect evidence of pulmonary hypertension several years after pneumonectomy ${ }^{26}$; no studies have looked at early haemodynamic changes after lung resection.

We conclude that the fall in $\mathrm{FEV}_{1}$ is a poor predictor of the fall in exercise capacity after lung resection. The intensity of dyspnoea for a given work load increases after pneumonectomy but not after lobectomy. This cannot be explained by a change in ventilation for a given work load. Despite the decreased ventilatory capacity, symptoms from the exercising peripheral muscles are an important limiting factor of exercise capacity and may contribute to disability and handicap after lung resection.

This work was supported by grants from the Foundation JD Bégin of the Universite Laval and the Association Pulmonair du Québec. PL has a scholarship for the Fonds de Recherche en Santé du Québec.

1 Ogilvie C, Harris LH, Meecham J, Ryder G. Ten years after pneumonectomy for carcinoma. Br Med J 1963;i:1111-5. 2 McIlroy MB, Bates DV. Respiratory function afte pneumonectomy. Thorax 1956;11:303-11.

3 Gaensler EA, Streider JW. Progressive changes in pulmonary function after pneumonectomy. $J$ Thorac Sur 1951;22:1-18.

4 Curtis JK, Bauer H, Rasmussen HK, Mendenhall JT. Studies of pulmonary function before and after pulmonary surgery in 450 tuberculosis patients. $J$ Thorac Surg 1959;37:148-65.

5 Tammeling GJ, Laros $\mathrm{CD}$. An analysis of the pulmonary function of ninety patients following pneumonectomy for tuberculosis. J Thorac Surg 1958;37:148-65.

6 Pianetto MB, Harris HA, Sweet HC. Changes in pulmonary function before and after pneumonectomy for pulmonary function before and after pneumonectomy for pulm

7 Corris PA, Ellis DA, Hawkins T, Gibson GJ. Use of radionuclide scanning in the preoperative estimation of pulmonary function after pneumonectomy. Thorax 1987 42:285-91.
8 Boushy SF, Billig DM, North LB, Helgasm AH. Clinical course related to preoperative and postoperative pulmonary function in patients with bronchogenic carmonary function in patients
cinoma. Chest 1971;59:383-91.

9 Black LF, Hyatt RE. Maximal respiratory pressure: normal values and relationship to age and sex. Am Rev Respir Dis 1969;99:696-702

10 Jones NL, Campbell EJM. Clinical exercise testing. 2nd ed. Philadelphia: Saunders, 1-82.

11 Borg G. Psychological bases of perceived exertion. Med Sci Sports Exerc 1982;14:377-81.

12 Berglund E, Birath G, Bjure J. Spirometric studies in norma subjects Part I. Forced expirograms in subjects between 7 and 70 years of age. Acta Med Scand 1963;173:186-99.

13 Jones NL, Makrides L, Hitchcock C, Chypchar T, McCartney N. Normal standards for an incremental progressive cycle ergometer test. Am Rev Respir Dis 1985;131:700-8.

14 Gandevia B, Hugh-Jones P. Terminology for measurement of ventilatory capacity. Thorax 1957;12:290-3.

15 Astrand PO, Rodahl K. Textbook of work physiology. Physiological basis of exercise. New York: McGraw Hill, 1977:188.

16 Legge JS, Palmer KNV. Effect of lung resection for bronchial carcinoma on pulmonary function in patients with and without chronic bronchitis. Thorax 1975;30:563-5.

17 Pineda H, Haas F, Axen K, Haas A. Accuracy of pulmonary function tests in predicting exercise tolerance in chronic obstructive pulmonary disease. Chest 1984;86:564-7.

18 Gorlin R, Knowles JH, Storey CF. Effects of thoracotomy on pulmonary function. Patients with localised pulmonary disease. J Thorac Surg 1957;34:242-8.

19 Hansen JE. Exercise testing. In: Clausen JL, ed. Pulmonary function testing: guidelines and controversies. New York: Academic Press, 1982:274.

20 Kyle SB, Smoak BL, Douglass LW, Deuster PA. Variability of responses across training levels to maximal treadmil exercise. J Appl Physiol 1989;67:160-6.

21 Silverman MT, Barry J, Hellerstein HK, Kelsen SG Variability of the perceived sense of effort during exercise in patients with chronic obstructive lung disease [abstract]. Am Rev Respir Dis 1987;135:A360.

22 LeBlanc P, Bowie DM, Summers E, Jones NL, Killian KJ Breathlessness and exercise in patients with cardiorespiratory disease. Am Rev Respir Dis 1986;133:21-5.

23 LeBlanc P, Liao ML, Jones NL, Killian KJ. Relationship between $\mathrm{FEV}_{1}$ and exercise capacity [abstract]. Am Rev Respir Dis 1985;131:A308.

24 Jones NL, Kearon MC, LeBlanc P, Martin D, Campbell EJM, Killian KJ. Symptoms limiting activity in chronic airflow obstruction [abstract]. Am Rev Respir Dis airflow obstructio

25 Gandevia SC, McKenzie DK, Neering IR. Endurance properties of respiratory and limb muscle. Respir Physiol 1983;53:47-51.

26 Fry WA, Archer FA, Adams WE. Long-term clinicalpathologic study of the pneumonectomy patient. Dis Chest 1967;51:720-7. 